\title{
The correlation between score-based protocol for equine joint assessment and subsequent arthroscopic intervention outcomes
}

\section{Protocolo de avaliação baseado em escore das afecções articulares em equinos e correlação com o resultado do tratamento por artroscopia}

\author{
Marilene Machado Silva ${ }^{1}$; Stefano Carlo Filippo Hagen²; Cynthia do Padro Vendruscolo \\ Raquel Yvonne Arantes Baccarin ${ }^{3}$; Júlio David Spagnolo4; Ana Lúcia Miluzzi Yamada²; \\ Fernanda de Castro Stievani ${ }^{5}$; Luis Claudio Lopes Correia da Silva²* (D)

\begin{abstract}
${ }^{1}$ Universidade Federal do Paraná, Faculdade de Medicina Veterinária, Setor Palotina, Palotina - PR, Brasil ${ }^{2}$ Universidade de São Paulo, Faculdade de Medicina Veterinária e Zootecnia, Departamento de Cirurgia, São Paulo - SP, Brasil ${ }^{3}$ Universidade de São Paulo, Faculdade de Medicina Veterinária e Zootecnia, Departamento de Clínica Médica, São Paulo - SP, Brasil ${ }^{4}$ Universidade de São Paulo, Faculdade de Medicina Veterinária e Zootecnia, Hospital Veterinário, São Paulo - SP, Brasil Botucatu - SP, Brasil
\end{abstract} \\ ${ }^{5}$ Universidade Estadual Paulista, Faculdade de Medicina Veterinária e Zootecnia, Departamento de Cirurgia e Anestesiologia Veterinária,
}

\begin{abstract}
This study aimed to grade joint abnormalities in horses submitted to therapeutic arthroscopy using score-based protocols for equine joint assessment, correlated with arthroscopic treatment outcomes and owner satisfaction. In this prospective study, we evaluated 126 joints of athletic horses referred for arthroscopy. The joints were scored according to findings of medical history and physical, radiographic, ultrasonographic and arthroscopic examination. Lameness, positive response to flexion test and decreased maximum joint flexion angle were detected in more than $50 \%$ of joints. Soft tissue swelling, sclerosis, subchondral bone osteolysis and single osteochondral fragments were the most common radiographic findings. Ultrasonographic examination revealed changes in synovial fluid volume and appearance, and subchondral bone irregularities. Increased vascularity of the synovial villi, chondral fibrillation, chondral fissures and superficial cartilage erosions were the most significant arthroscopic findings. The approaches that demonstrated greater sensitivity and correlation with treatment outcome and owner satisfaction were medical history, ultrasonographic and arthroscopic examination. The scoring protocol employed to grade joint abnormalities enabled the creation of a joint score system for the objective assessment, thus determining the most frequent findings and establishing an injury severity score for each joint.
\end{abstract}

Keywords: Arthroscopy. Joint. Radiography. Score. Ultrasonography.

\section{RESUMO}

O objetivo desse estudo foi avaliar as anormalidades articulares observadas em equinos submetidos à artroscopia terapêutica, utilizando protocolos baseados em pontuações e correlacionando os resultados do tratamento cirúrgico com a satisfação do proprietário. Neste estudo prospectivo, foram avaliadas 126 articulações de cavalos atletas, encaminhados para artroscopia. As articulações foram pontuadas de acordo com os achados da anamnese e exame físico, exame radiográfico, exame ultrassonográfico e avaliação artroscópica. A claudicação, resposta positiva ao teste de flexão e diminuição do ângulo máximo de flexão articular foram detectados em mais de $50 \%$ das articulações. Aumento de volume dos tecidos moles, esclerose subcondral, osteólise subcondral e fragmentos osteocondrais únicos foram os achados radiográficos mais comuns. O exame ultrassonográfico revelou, com frequência, as alterações no volume e na aparência do líquido sinovial, além de irregularidades osteocondrais. $\mathrm{O}$ aumento da vascularização das vilosidades sinoviais, fibrilação condral, fissuras condrais e erosões superficiais da cartilagem foram os achados artroscópicos mais significativos. As abordagens diagnósticas que demonstraram maior sensibilidade e melhor correlação entre o resultado do tratamento e satisfação do proprietário foram história médica, exame ultrassonográfico e artroscópico. O protocolo de avaliação utilizado, baseado em um sistema de pontuação das anormalidades articulares observadas em cada exame, permitiu uma avaliação objetiva, ressaltando os achados mais frequentes e estabelecendo um escore de gravidade da lesão para cada articulação.

Palavras-chave: Articulação. Artroscopia. Escore. Radiografia. Ultrassonografia. 
Correspondence to:

Luis Claudio Lopes Correia da Silva

Universidade de São Paulo, Faculdade de Medicina Veterinária e Zootecnia, Departamento de Cirurgia

Av. Prof. Dr. Orlando Marques de Paiva, 87, Cidade Universitária CEP: 05508 270, São Paulo - SP, Brasil

e-mail: silvalc@usp.br

Received: May 24, 2019

Approved: December 11, 2019

How to cite: Silva MM, Hagen SCF, Vendruscolo CP, Baccarin RYA, Spagnolo JD, Yamada ALM, Stievani FC, Silva LCLC. The correlation between score-based protocol for equine joint assessment and subsequent arthroscopic intervention outcomes. Braz J Vet Res Anim Sci. 2019;56(4):e158072. https://doi.org/10.11606/ issn.1678-4456.bjvras.2019.158072

\section{Introduction}

The chronic and incapacitating nature of equine osteochondral disorders is often associated with declining athletic performance, owner disappointment and financial losses. Osteochondral lesions may be detected and evaluated in several manners, including physical examination, radiographic and sonographic assessment, synovial fluid analysis, computed tomography, magnetic resonance imaging and arthroscopy. Detailed examination of the musculoskeletal system, including medical history, careful physical examination and imaging modalities is required to locate the injury and determine the site of pain and lameness (Davidson, 2018; McIlwraith et al., 2011; McIlwraith et al., 2012; Minshall, 2008; Souza, 2016)

Diagnostic imaging plays a vital role in joint disease identification and classification, and several complementary modalities may be combined for accurate diagnosis (Machado et al., 2016). Radiography is undeniably useful and practical but does not provide detailed imaging of soft tissues (Baccarin et al., 2012; Lawson et al., 2012). Ultrasonography permits rapid multiplane imaging (Keen \& Conaghan, 2009; Nelson et al., 2016) and is an additional part of equine practice, with wide application in chondral surface and subchondral plate assessment, as well as imaging of tendons, ligaments and periarticular structures along the front and hind limbs (Debastiani et al., 2014; Denoix \& Audigié, 2001; Rasera et al., 2007; Reef et al., 2004; Minshall, 2008). Arthroscopic assessment allows direct visualization of intra-articular structures and is critical for characterization of several pathological conditions and estimation of chondral injury, severity and extension. A major advantage of arthroscopy is the possibility to combine diagnostic and therapeutic interventions in a single procedure (Muttini et al., 2003; Nelson et al., 2016; Vanderperren et al., 2009).

Standardized approaches to joint disease assessment are particularly helpful for classification of physical examination and imaging findings, prognostic estimation and owner understanding. Assessment protocols based on scoring systems play a key role in objective grading of injury, with substantial contributions to purchase exam as well as clinical, experimental and epidemiological studies (Lepeule et al., 2013). This study aimed to grade articular injuries in horses submitted to therapeutic arthroscopy using a scoring system. A joint score based on medical history, physical, radiographic and ultrasonographic examination findings was developed to add objectivity to joint assessment. Thus, it will be possible to determine the most frequent findings and establish an injury severity score for each joint. With this score-based protocol, correlations with arthroscopic treatment outcome and owner satisfaction can also be investigated.

\section{Materials and Methods}

This study was approved by the Ethics Committee for the Use of Animals of the School of Veterinary Medicine and Animal Science - University of São Paulo (protocol No. 2093/2010). This prospective study was based on data compiled during the examination of horses affected with non-infectious joint diseases referred to the Equine Internal Medicine and Surgery Services of Veterinary Hospital -FMVZ/USP for therapeutic arthroscopy. Horses were submitted to clinical and imaging assessment and then to arthroscopy. The sample comprised 80 horses of different breeds and 126 joints (also considering more than one joint/animal: metacarpophalangeal - MCP, metatarsophalangeal - MTP or tibiotarsal- TT). Injuries were scored according to findings at each stage of the examination procedure: medical history, physical examination, radiographic, ultrasonographic and arthroscopic examination.

\section{Medical history and physical examination}

Medical history data was acquired by a questionnaire with scores, reported by their veterinarian at the veterinary hospital reception desk. Medical history findings were scored 0 to 13 (Table 1). Physical examination was performed immediately after admission. The following parameters were investigated in the physical examination: lameness grade, response to flexion test, maximum joint flexion angle increase (with goniometer), joint perimetry increase (tape measure), surface temperature increase 
Table 1 - Medical history questionnaire data

\begin{tabular}{|c|c|}
\hline \multicolumn{2}{|l|}{ Disease progression time (DP) } \\
\hline Up to 7 days & 1 \\
\hline Between 8 and 30 days & 2 \\
\hline Between 31 and 180 days & 3 \\
\hline More than 180 days & 4 \\
\hline \multicolumn{2}{|l|}{ Response to previous treatment (PT) } \\
\hline No treatment & 0 \\
\hline $\begin{array}{l}\text { Total improvement after use of non-steroidal } \\
\text { anti-inflammatory drug, joint injection or ice and rest }\end{array}$ & 1 \\
\hline $\begin{array}{l}\text { Lameness decrease after use of non-steroidal } \\
\text { anti-inflammatory drug, joint injection or ice and rest }\end{array}$ & 2 \\
\hline Without any improvement & 3 \\
\hline \multicolumn{2}{|l|}{ Previous medical history (PMH) } \\
\hline First episode of musculoskeletal disease & 1 \\
\hline Between 2 and 3 episodes & 2 \\
\hline More than 3 episodes & 3 \\
\hline \multicolumn{2}{|l|}{ Evolution (E) } \\
\hline No lameness & 0 \\
\hline Improvement & 1 \\
\hline Stabilized & 2 \\
\hline Worsened & 3 \\
\hline Total & 13 \\
\hline
\end{tabular}

(laser thermometer), pain, consistency and joint stability (by palpation and manipulation). Lameness degree was determined by animal exam at the walk and trot and graded according to Table 2. As Table 2 shows, findings were scored 0 to 30. All parameters were compared to normal and healthy contralateral limb of the same animal. If the condition was bilateral, the increase was measured from the mean of MCP, MTP or TT healthy joints examined during the study.

\section{Imaging assessment}

Imaging findings were scored by at least three examiners blinded to clinical data. Given the dynamic nature of ultrasonography, sonographic images were analyzed simultaneously by different examiners during the exam. Radiographic and arthroscopic images were stored in digital systems for future analysis. Radiographic examination (Poskom PXP 20HF X-Ray; Fujifilm, FCR IP cassette, model CC; imaging plates: $24 \times 30 \mathrm{~cm}$ or $18 \times 24 \mathrm{~cm}$; IP reader: IP, Fujifilm FCR capsule X; Poskom Co Ltd South Korea) included lateromedial (LM); dorsopalmar (DPa)/dorsoplantar (DPl); dorsolateral-palmaromedial(DL-PaLO)/plantaromedial(DL-PILO) and dorsomedial-palmarolateral (DM-PaLO)/plantarolateral (DM-PILO) views. Radiographic images were scored from 0 to 48 (Table 3) using an adapted scoring protocol (Kirker-Head et al., 2000; Martins, 2010). Ultrasonographic examinations (ESAOTE MyLab30Vet Ultrasound system, linear transducer 6 to $18 \mathrm{MHz}$ - ESAOTE Italy) were carried
Table 2 - Parameters evaluated by physical examination of diseased joints and proposed classification of findings

\section{Lameness score (LAME)}

No detectable lameness under any circumstances 0

Lame apparent at trot, but not at walk $\quad 1$

Lameness perceptible at walk, with no obvious head 2 movement

Lameness evident at walk, with typical head movement 3

Non-weight bearing lameness

4

Negative response 0

Positive response; one-grade increase compared to 1

baseline lameness

Positive response; two-grade increase compared to 2

baseline lameness

Positive response; three-grade increase compared to 3

baseline lameness

Non-weight bearing lameness $\quad 4$

\begin{tabular}{ll}
\hline \multicolumn{1}{c}{ Maximum flexion angle increase (degrees)(FLEX) } \\
\hline Less than $5^{\circ}$ & 0 \\
6 to $10^{\circ}$ & 1 \\
11 to $15^{\circ}$ & 2 \\
16 to $20^{\circ}$ & 3 \\
Equal to or greater than $21^{\circ}$ & 4 \\
\hline
\end{tabular}

Equal to or greater than $21^{\circ}$

Less than $0.5 \mathrm{~cm}$

0

0.6 to $2.0 \mathrm{~cm}$

2.1 to $4.0 \mathrm{~cm}$

4.1 to $6.0 \mathrm{~cm}$

Equal to or greater than $6.1 \mathrm{~cm}$

-

(1)

(n)

\begin{tabular}{ll}
\hline \multicolumn{1}{c}{ Surface temperature increase $\left({ }^{\circ} \mathrm{C}\right)$ (TEMP) } & 4 \\
\hline No temperature increase & 0 \\
Up to $1.5^{\circ} \mathrm{C}$ temperature increase & 1 \\
1.6 to $2.5^{\circ} \mathrm{C}$ temperature increase & 2 \\
2.6 to $3.5^{\circ} \mathrm{Ctemperature} \mathrm{increase}$ & 3 \\
Temperature increase equal to or greater than $3.6^{\circ} \mathrm{C}$ & 4 \\
\hline
\end{tabular}

\begin{tabular}{lc}
\hline \multicolumn{1}{c}{ Joint pain (PAIN) } & \\
\hline No response to palpation & 0 \\
Limb tension in response to joint palpation & 1 \\
Limb contraction and discomfort in response to joint & 2 \\
palpation & \\
Limb retraction in response to palpation & 3 \\
Flight reaction when touched by examiner & 4 \\
\hline \multicolumn{2}{c}{ Consistency on joint palpation (CONS) } \\
\hline Unchanged Joint stability (JSTAB) & 0 \\
Fluctuant & 1 \\
Crepitating & 2 \\
\hline Absence of lateral movement & 0 \\
Presence of lateral movement & 4 \\
Total & 30 \\
\hline
\end{tabular}

out in B and Power Doppler mode. All joint surfaces were submitted to longitudinal and cross-sectional imaging with the joint in the weight-bearing and flexed position. Sonographic images were scored 0 to 34 , according to parameters demonstrated in Table 4. Arthroscopic procedures were performed for joint inspection and therapeutic purposes (Tele Pack Vet X Led, RP 100, Karl Storz). A cumulative score 
Table 3 - Parameters evaluated by radiographic examination of diseased joints and proposed classification of findings (Kirker-Head et al., 2000; Martins, 2010)

Soft tissue swelling (STS)

None

Mild localized soft tissue swelling

0

Mild diffuse soft tissue swelling

Moderate soft tissues swelling

Marked soft tissues swelling

Soft tissue swelling extending beyond the target joint

Soft tissue mineralization (STM)

None

Suspected

Areas of diffuse or localized striation

Areas of localized increased density

Areas of diffuse increased density

Areas of diffuse, generalized increased density extending beyond the target joint

\section{Radiographic joint space widening (JSPAW)}

Normal

Suspected

Mild

Evident; no loss of joint congruence

Marked; partial loss of joint congruence(subdislocation)

Marked; total loss of joint congruence (dislocation)

Radiographic joint space narrowing (JSPAN)

Normal

Suspected

Mild symmetrical or asymmetrical narrowing

Moderate symmetrical or asymmetrical narrowing, with no loss of definition

Marked, ill-defined narrowing

Undefined joint space

\section{Osteophytes and bone proliferation (OSTEO)}

None

Small bony projection affecting one bone surface

Small bony projections between bone surfaces

Prominent, well-organized, localized bony projection

Prominent, organized bony projections apparent in more than one radiographic view

Extensive, irregular bony projections apparent in more than one radiographic view

Enthesophytes (ENTHESO)

None

Mild nebulosity at joint capsule or ligament attachment sites

Calcified lines or small calcified tissue bridge at joint capsule or ligament attachment sites

Easily recognizable, organized bony projection at joint capsule or ligament attachment sites

Evident, irregular bony projection at joint capsule or ligament attachment sites

Extensive, disorganized bone response at joint capsule or ligament attachment sites

Subchondral bone sclerosis (SSCL)

None

Suspected or mildly increased subchondral bone plate density

Localized sclerotic areas

Moderate, diffuse subchondral sclerosis, with heterogeneously distributed radiographic density

Moderate, diffuse subchondral sclerosis, with homogeneously distributed radiographic density

Evident, diffuse subchondral sclerosis extending to epiphyseal trabecular bone

\section{Subchondral bone lysis (SBL)}

\section{None}

Small, mildly irregular subchondral bone margin

Localized superficial subchondral bone erosion

Generalized superficial subchondral bone erosion

Prominent, irregular erosion or cystic lysis at subchondral bone margin or extending slightly into the epiphysis

Severe erosion or cystic lesion extending throughout the epiphysis 
Table 3 - Continued...

\section{Osteochondral fragments (FRAGM)}

None

Single subtle, ill-defined, non-displaced osteochondral fragment

Single subtle, well-defined, non-displaced osteochondral fragment

Two well-defined, non-displaced fragments

Multiple non-displaced fragments or displaced fragment

Size of osteochondral fragment (FRAGS)

None

Smaller than or equal to $5 \mathrm{~mm}$

Between 6 and $10 \mathrm{~mm}$

Between 11 and $15 \mathrm{~mm}$

Larger than $15 \mathrm{~mm}$

Total

0

1

2

3

4

Table 4 - Parameters evaluated by ultrasonographic examination of diseased joints and proposed classification of findings

\section{Synovial fluid appearance (SFA)}

Normal

Anechoic synovial effusion

Heterogeneous, mostly anechoic fluid

Predominance of heterogeneous amorphous material and anechoic fluid

Heterogeneous amorphous material and/or fluid containing dense material and suspended hyper reflective foci

\section{Synovial fluid volume (SFV)}

Unchanged

Increased - up to half the physiologic volume

Increased - up to twice the physiologic volume

Increased - more than twice the physiologic volume

Increased - more than three times the physiologic volume

Joint capsule thickness (JCT)

Unchanged

Mild localized thickening

Generalized thickening

Generalized thickening greater than

\begin{tabular}{|c|c|}
\hline Generalized thickening greater than & 3 \\
\hline \multicolumn{2}{|c|}{ Joint capsule attachment (JCA) } \\
\hline Smooth & 0 \\
\hline Mild irregularity & 1 \\
\hline Evident irregularity & 2 \\
\hline Marked irregularity with increased blood vessel flow/width & 3 \\
\hline \multicolumn{2}{|c|}{ Joint capsule appearance (JCAP) } \\
\hline Homogeneous echogenicity & 0 \\
\hline Localized hypoechoic areas & 1 \\
\hline Hypoechoic areas containing hyperechoic foci & 2 \\
\hline \multicolumn{2}{|c|}{ Periarticular ligament appearance (LIGA) } \\
\hline Unchanged & 0 \\
\hline Heterogeneous with hypoechoic areas & 1 \\
\hline Heterogeneous with hyperechoic areas & 2 \\
\hline Massive damage and tear & 3 \\
\hline
\end{tabular}

Periarticular ligament origin/attachment (LIGO)

Unchanged-smooth

Presence of irregularities

0

Bone proliferation

Marked bone proliferation

2

Marked bone proliferation and fragments

Joint capsule and synovial membrane vascularity (VASC)

No detectable blood flow

Visible vascularity/small numbers of scattered color dots

Increased vascularity 
Table 4 - Continued...

\begin{tabular}{|c|c|}
\hline \multicolumn{2}{|l|}{ Articular cartilage thickness (CART) } \\
\hline Well-defined articular cartilage. Continuous, smooth, easily recognizable & 0 \\
\hline Articular cartilage difficult to distinguish; smooth, continuous portions detected in more than $50 \%$ of scanned surface & 1 \\
\hline Articular cartilage difficult to distinguish; rough, discontinuous portions detected & 2 \\
\hline Undistinguishable articular cartilage; fragments in the synovial fluid & 3 \\
\hline Undistinguishable articular cartilage and diffuse subchondral bone surface changes & 4 \\
\hline \multicolumn{2}{|l|}{ Subchondral bone surface (SBS) } \\
\hline Smooth surface & 0 \\
\hline Irregular surface & 1 \\
\hline Areas of flattening & 2 \\
\hline \multicolumn{2}{|l|}{ Subchondral bone osteophytosis (SBO) } \\
\hline Smooth articular margin & 0 \\
\hline Rough articular margin & 1 \\
\hline Osteophytosis & 2 \\
\hline Large and/or fragmented osteophytes & 3 \\
\hline Total & 34 \\
\hline
\end{tabular}

was used to grade articular surface findings. Arthroscopic findings were scored from 0 to 48 , according to parameters outlined in Table 5.

\section{Treatment outcomes}

A standardized questionnaire was used to determine owner satisfaction or dissatisfaction and arthroscopic treatment outcome.

\section{Statistics}

The medical history, physical examination, radiographic, ultrasonography and arthroscopic scores were submitted to analysis of variance (Repeated-Measures ANOVA). The intraclass correlation coefficient (ICC) was used to estimate inter-examiner agreement in radiographic and arthroscopic examinations. The logistic regression model and stepwise selection procedure (Venables \& Ripley, 2002) were used to predict treatment success and owner satisfaction. Model accuracy was tested using ROC (Receiver Operating Characteristics) curve analysis. The level of significance was set at $5 \%(\mathrm{p}<0.05)$. Statistical tests were performed using R software (Foundation for Statistical Computing, version 3.0.3, R Core Team, 2014).

\section{Results}

Most horses in this sample were Brazilian Sport Horse (32 out of $80 ; 40 \%$ ) or Lusitano Horse (27 out of 80; 33.8\%). The other breeds (21 out of $80 ; 26.2 \%)$ were American Trotter, Mangalarga Marchador, Mangalarga Paulista, Thoroughbred, Campolina, Quarter Horse and English Saddle. Horses were aged four years and ten months on average. Joint distribution was as follows: MCP (thoracic limb fetlock; 26 out of 126), MTP (pelvic limb fetlock; 22 out of 126) and TT (tarsus; 78 out of 126). After performing all examinations, the most common joint disease diagnosed in this study (83.8\% of joints) was osteochondritis dissecans (OCD) with or without concurrent osteoarthritis. Other conditions, such as abnormal joint conformation and villonodular synovitis, were occasionally detected.

\section{Medical history and physical examination}

Most findings were consistent with the early phase of the disease according to the scoring protocol proposed (disease progression time up to 7 days; $58.1 \%$ of cases), including cases referred due to radiographic findings in pre- or post-purchase examination; $73.4 \%$ of joints had not been previously treated and, in $83.8 \%$ of joints, horses were referred after the first manifestation of a musculoskeletal disorder. Lameness was not reported by $50.3 \%$ of owners (Figure 1). In more than $50 \%$ of joints, physical examination revealed some degree of change in the following parameters: lameness score, response to flexion test, maximum flexion angle and surface temperature. Mean maximum joint flexion angle and joint perimetry documented in normal/healthy joints were as follows: $114^{\circ}$ and $27.3 \mathrm{~cm}$ (MCP joint), $93^{\circ}$ and $29.3 \mathrm{~cm}$ (MTP joint), and $51^{\circ}$ and $42.4 \mathrm{~cm}$ (TT joint). This reference values were the standards in comparison with the affected joints. Score 1 lameness was most commonly detected (28.4\% of animals) (Figure 2).

\section{Radiographic examination}

The following radiographic parameters were scored zero in most joints: soft tissue mineralization, joint space widening/narrowing and enthesophyte formation. Mild diffuse swelling was the most common soft tissue abnormality (37.4\% of joints). Other common radiographic findings were localized areas of subchondral bone sclerosis and localized, superficial subchondral bone erosion $(40 \%$ and $67 \%$ of 
Table 5 - Parameters evaluated by arthroscopic examination of diseased joints and proposed classification of findings

\begin{tabular}{|c|c|}
\hline \multicolumn{2}{|l|}{ Color of synovial villi (CSV) } \\
\hline Unchanged & 0 \\
\hline Evident blood vessels & 1 \\
\hline Marked vascularity; homogeneous red color & 2 \\
\hline \multicolumn{2}{|l|}{ Volume and number of synovial villi (VSN) } \\
\hline Unchanged & 0 \\
\hline Increased volume; no change in number & 1 \\
\hline Increased volume; mildly increased number & 2 \\
\hline Evidently increased volume and number & 3 \\
\hline Difficult visualization of articular surfaces in liquid medium & 4 \\
\hline \multicolumn{2}{|l|}{ Articular surface (AS) } \\
\hline Unchanged & 0 \\
\hline Focal fibrillation (FIBRIF) & 1 \\
\hline Focal fissure (FISSUF) & 1 \\
\hline Diffuse fibrillation (FIBRID) & 2 \\
\hline Multiple fissures (MF) & 2 \\
\hline Presence of fibrin (FIBRIN) & 2 \\
\hline Superficial or focal erosion (ESF) & 2 \\
\hline Presence of osteophytes (OSTE) & 3 \\
\hline Diffuse superficial erosion (EDS) & 3 \\
\hline Deep focal erosion (EDF) & 3 \\
\hline Focal eburnation (EBURF) & 3 \\
\hline Focal osteonecrosis (ONF) & 3 \\
\hline Deep diffuse erosion (EDD) & 4 \\
\hline Diffuse eburnation (EBURD) & 4 \\
\hline Diffuse osteonecrosis (OND) & 4 \\
\hline Synovial villi adhesion (ADHEV) & 4 \\
\hline Pannus (PANUS) & 4 \\
\hline \multicolumn{2}{|l|}{ Number of fragments (FRAGN) } \\
\hline No fragments & 0 \\
\hline 1 fragment & 1 \\
\hline 2 fragments & 2 \\
\hline 3 fragments & 3 \\
\hline 3 or more fragments & 4 \\
\hline Loose articular fragment (FRAGL) & 4 \\
\hline \multicolumn{2}{|l|}{ Fragment size (FRAGS) } \\
\hline No fragments & 0 \\
\hline Fragments measuring up to $5 \mathrm{~mm}$ & 1 \\
\hline Fragments measuring 5 to $10 \mathrm{~mm}$ & 2 \\
\hline Fragments larger than 10 to $15 \mathrm{~mm}$ & 3 \\
\hline Fragments larger than $15 \mathrm{~mm}$ & 4 \\
\hline Total & 48 \\
\hline
\end{tabular}

joints, respectively). Single, well-defined, non-displaced osteochondral fragments were present in $47.3 \%$ of joints; fragments were smaller than $5 \mathrm{~mm}$ in $30 \%$ of cases.

\section{Ultrasonographic examination}

Disorders in synovial fluid appearance, synovial fluid volume and subchondral bone surface were more prevalent in joints scoring 1 to 4 . Predominance of amorphous material and up to $50 \%$ increase in volume was the most common synovial fluid findings ( $40 \%$ of joints). Irregular surface was the most common subchondral bone abnormality detected (41.3\% of joints) (Figures 3 and 4 ).

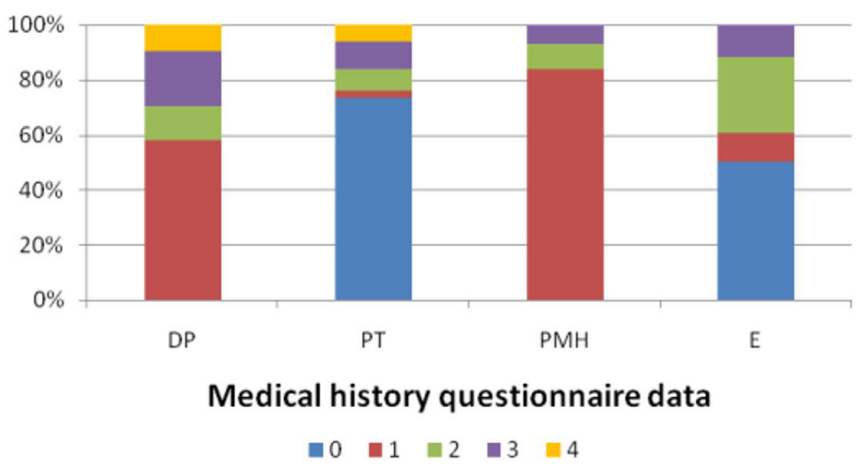

Figure 1 - Medical history questionnaire data: joint distribution (\%) according to parameters/scores evaluated in medical history (Table 1): DP - disease progression time; PT - response to previous treatment; PMH - previous medical history; E - evolution.

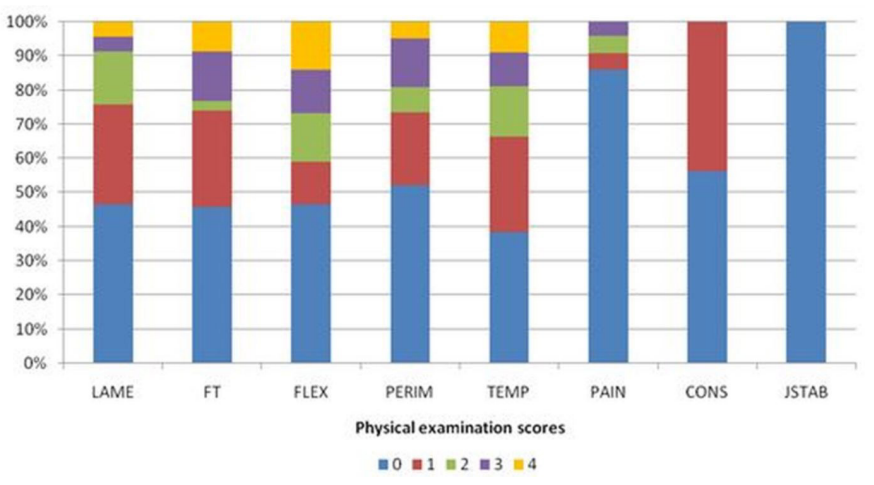

Figure 2 - Physical examination results: joint distribution (\%) according to parameters/scores assessed on physical examination (Table 2): LAME - lameness score; FT - flexion test; FLEX -maximum flexion angle increase; PERIM - perimetry increase; TEMP - surface temperature increase; PAIN - pain on palpation; CONS - consistency on palpation; JSTAB - joint stability.

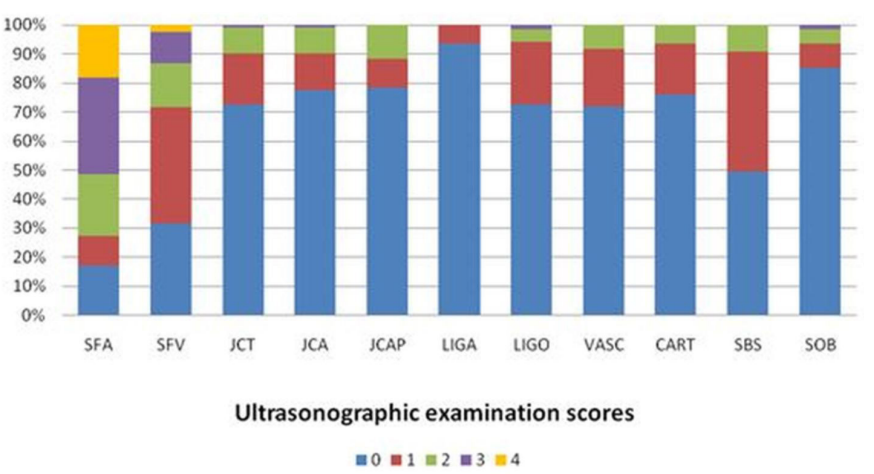

Figure 3 - Ultrasonographic examination results: joint distribution (\%) according to parameters/scores assessed on ultrasonographic examination (Table 4): SFA - synovial fluid appearance; SFV - synovial fluid volume; JCT - joint capsule thickness; JCA - joint capsule attachment; JCAP - joint capsule appearance; LIGA - periarticular ligament appearance; LIGO - periarticular ligament origin/attachment; VASC - joint capsule and synovial membrane vascularity; CART - articular cartilage thickness; SBS - subchondral bone surface; $\mathrm{SBO}$ - subchondral bone osteophytosis. 

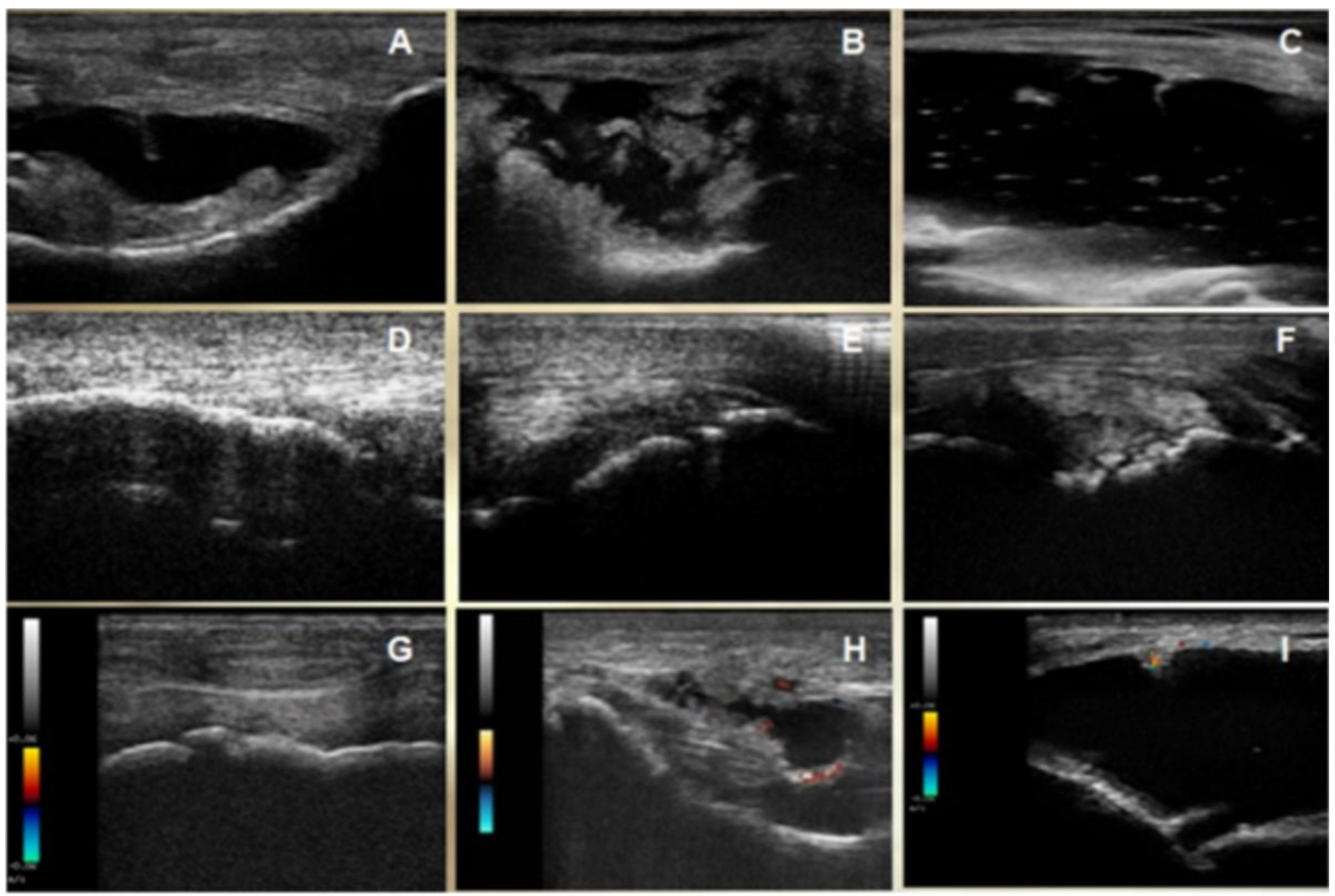

Figure 4 - Sonographic images: sonographic images showing increasingly severe synovial fluid change (volume and appearance) (A, B and C); irregularities at periarticular ligament attachment site (D, E and F) and synovial membrane vascularity (G, H and I).

\section{Arthroscopic examination}

Presence of evident blood vessels was the most common arthroscopic finding in item "color of synovial villi" (65.8\%). Most joints scoped (50\%) scored 3 in item "evidently increased synovial villi volume and number". Focal abnormalities, such as fibrillations (75.8\%), erosions (70\%) and fissures (70\%), were the most common articular surface findings in arthroscopic assessment. Single (61.7\%) and non-displaced (86.7\%) osteochondral fragments were also often detected during arthroscopic assessment (Figure 5).

\section{Correlation between assessment methods, respective scores and inter-examiner agreement}

Regarding the sensitivity to surgical access, the mean radiographic scores attributed to palmar/plantar fetlock and TT joint injuries were higher $(\mathrm{p}=0.05)$ compared to dorsal fetlock injuries. Mean sonographic scores attributed to dorsal or palmar/plantar fetlock injuries were higher ( $\mathrm{p}=0.011)$ compared to tibiotarsal lesions. In contrast, mean arthroscopic scores attributed to tibiotarsal injuries were higher $(\mathrm{p}<0.001)$ compared to dorsal or palmar/plantar fetlock lesions. Inter-examiner agreement was low in the following cases: radiographic examination of the MTP joint and arthroscopic examination of the TT joint. Medical history/physical examination/radiographic examination and radiographic/arthroscopic examination were the only positive correlations detected $(\mathrm{p}=0.01$ and $\mathrm{p}=0.05$, respectively).

\section{Satisfaction percentage and correlation between scores and owner satisfaction}

A small percentage of owners (18\%) showed dissatisfaction of treatment outcome. Mean scores derived from different assessment methods were lower when treatment outcome was satisfactory, i.e., horses with less articular abnormalities and lower scores prior to arthroscopy had a better prognosis. Joints scoring higher in arthroscopic examination had a poorer prognosis (Figure 6). Owners of horses with MTP and palmar/plantar fetlock injuries showed complete satisfaction after arthroscopic treatment. However, post-treatment of TT and dorsal MCP joints demonstrated $26.4 \%$ and $9.1 \%$ of owner dissatisfaction. 

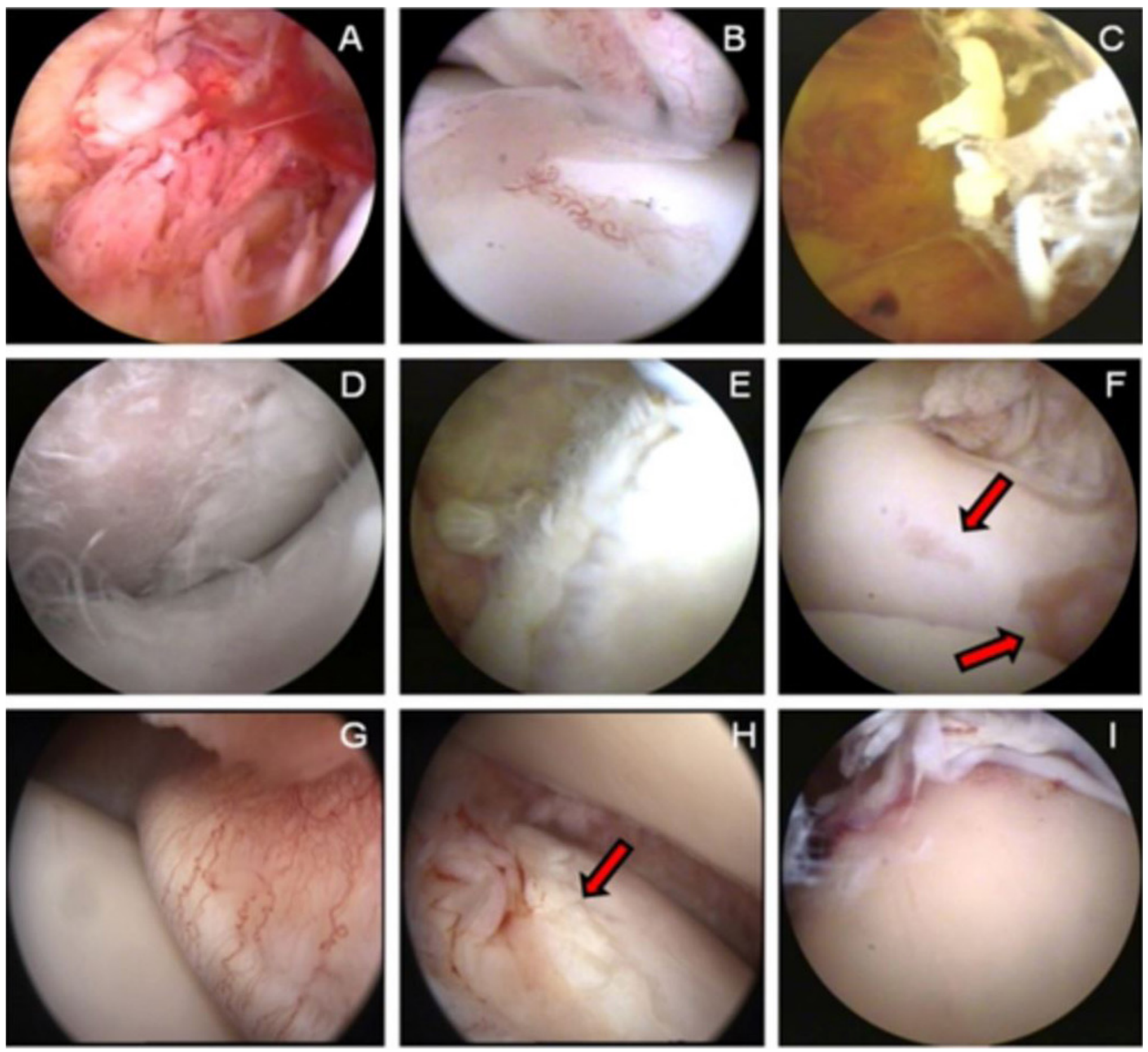

Figure 5 - Arthroscopic images: arthroscopic images showing evident vascularity of synovial villi (A and B); synovial villi projecting into the joint space (C); deep diffuse erosion (D); diffuse fibrillation (E); focal superficial (upper arrow) and deep (lower arrow) erosions (F); pannus (G); fissure line on articular cartilage (arrow) (H); eburnation (I).

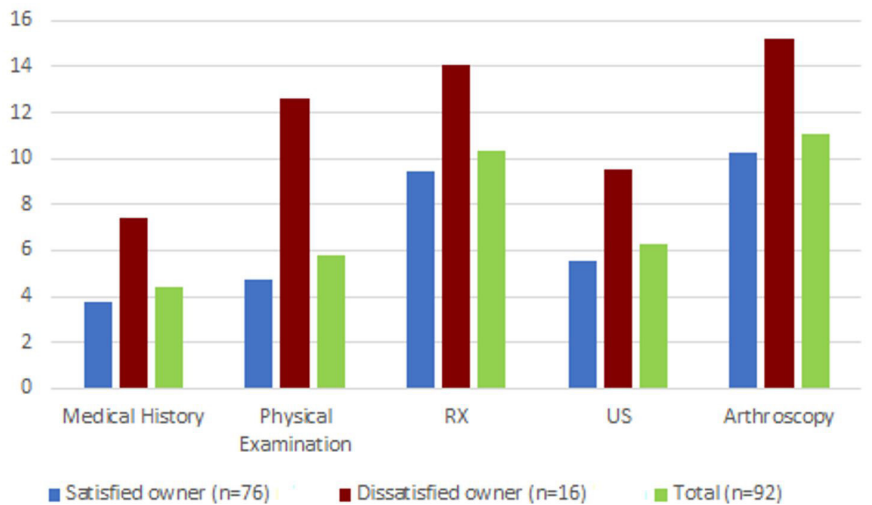

Figure 6 - Comparison of mean scores of joints (score-based protocol) of each assessment (Tables 1 to 5) according to owner satisfaction after arthroscopy treatment (RX - Radiographic examination; US - Ultrasonographic examination).
The following scores were associated with arthroscopic treatment outcome (logistic regression analysis): medical history, ultrasonographic and arthroscopic examination. The probability of owner dissatisfaction increased $17.8 \%$ after 1-point increase in medical history; $19.3 \%$ after 1-point increase in sonographic examination, and $21.3 \%$ after 1-point increase in the arthroscopic examination. ROC analysis was used to estimate the accuracy ( $\mathrm{AUC}=0.80 ; 95 \%$ confidence interval $0.957-0.643$ ) of maximum medical history, ultrasonographic and arthroscopic scores in predicting treatment outcome. For practical purposes, total scores rather than individual, assessment method-specific scores are recommended. Total scores can be calculated using the following equation: 
Pred_lin $=-5.6542+0.1641 *$ HISTORY $+0.1768 *$ $\mathrm{US}+0.1935 *$ ARTHRO

For example: a joint scoring 7 in "medical history", 9 in "ultrasonographic examination" and 10 in "arthroscopy" would have a $27 \%$ chance of owner dissatisfaction regarding treatment outcome.

\section{Discussion}

OCD injuries with or without osteoarthritis were detected in most joints in this study and manifested as clinical cases with a history of previous radiographic disorders detected in purchase exam, lack of previous treatment and short progression time. Physical examination often revealed lameness and joint effusion.

Radiographic and ultrasonographic examinations were more sensitive for detection of joint swelling compared to circumference measurements $(\mathrm{cm})$ taken during physical examination and are thought to accurately reflect synovial effusion in non-infectious joint diseases (Minshall, 2008; Vanderperren \& Saunders, 2009b; Vanderperren et al., 2009). Fluctuant consistency was detected on palpation of $43.8 \%$ of joints in this study and is also consistent with localized joint effusion typical of the early phase of joint disease (Souza, 2016). Radiographic assessment revealed that subchondral bone lesions were closely related to the site of osteochondral fragmentation. However, early patient referral may have prevented disease progression; therefore, these lesions were attributed low radiographic scores. Radiographic disorders are often difficult to detect in young animals starting training and in the early phases of joint disease (McIlwraith et al., 2012).

Jacquet et al. (2013) reported 8.7\% and 9\% incidence of osteochondral fragments in the dorsal and plantar aspect of the MTP joint respectively, and 3.4\% incidence in the MCP joint of Selle Française horses. In contrast, $41.2 \%$ of fragments in this study were located at the plantar aspect of the MTP joint, compared to $10.7 \%$ at the palmar aspect of the MCP joint. However, most horses in this study were either Lusitano or Brazilian Sport Horses. Inter-breed differences have been reported (Jacquet et al., 2013). Therefore, both studies support the premise that the prevalence and distribution of osteochondral fragments and OCD lesions vary considerably between breeds, and hence across different athletic disciplines.

Joint inflammation promotes synovial vascularity and hypertrophy. Fibrillation, focal fissures and superficial articular cartilage damage are also thought to be early manifestations of joint disease (Vanderperren \& Saunders, 2009b; Vanderperren et al., 2009; Kidd et al., 2001; Souza,
2016). These were the most common arthroscopic and sonographic (particularly power doppler sonography) findings in this study, again reflecting early case referral. Early referral is critical to prevent irreversible degenerative lesions. Nevertheless, arthroscopy proved to be a very efficient method for detecting lesions, particularly in the TT joint. In this joint, other imaging modalities are less accurate due to superimposition of intra-articular structures. Combined imaging modalities, as well as standardized description and quantification of findings, are highly recommended for diagnosis of joint diseases (De Lasalle et al., 2016; Machado et al., 2016; Sarin et al., 2017). Arthroscopy exam in combination primarily with medical history and sonographic exam were shown to be useful for detecting injuries compared with other performed pre-arthroscopic assessments.

There was reduced agreement among the three blind examiners to clinical data in assessment of TT joint arthroscopy videos that may have reflected the greater complexity of this joint compared to the MCP / MTP joints. Also, examiners may have diverged regarding the distinction between focal and diffuse lesions. Distinction between focal and diffuse articular surface lesions was part of the assessment protocol proposed in this study, and diffuse lesions were scored higher. However, the logistic regression model employed was not impacted by the standard error of the intraclass correlation between examiners; therefore, the effect of scores on treatment outcome (expressed as owner satisfaction) could be estimated. Inter-examiner disagreement may also have reflected incorrect interpretation of less severe findings, as already described (Vanderperren \& Saunders, 2009a; Lepeule et al., 2013). However, these incidents do not interfere with the reliability of the scoring protocol proposed.

Animals with higher mean scores also showed owners dissatisfied with treatment outcome. However, when results were submitted to logistic regression analysis, greatest influencers were only medical history, ultrasonographic and arthroscopic examination. This analysis also demonstrated that medical history could be removed ( $\mathrm{p}=0.110)$, but this management would decrease test accuracy by $5 \%$. The significance of medical history for prognostic estimation resides in data such as disease progression; classification of lesions with more than 30-day progression as chronic (Baxter, 2011); and factors such as poor owner ability to recognize clinical manifestations of joint disease (Ireland et al., 2012). These manifestations may even go unnoticed (and therefore lameness will not be reported) in horses starting breaking or training or submitted to absolute rest. 
The contribution of ultrasonography to soft tissue assessment and the consequential starting point of joint inflammation have been widely reported (Reef et al., 2004). Also, periarticular tissues that cannot be assessed using arthroscopy are amenable to sonographic assessment, hence the value of this imaging modality in early recognition and determination of the extension of soft tissue lesions with potentially good or bad impacts on disease progression. Sonographic examination has demonstrated undeniable importance, sensitivity and large impact on treatment outcome and owner satisfaction. At the same time, results of this study suggest arthroscopy was associated with identification of a larger number of lesions and greater accuracy compared to other assessment methods employed. Consequently, we observed the relevance of arthroscopy for prognostic estimation, owner satisfaction and treatment outcome prediction.

\section{Conclusion}

The standardized score tables and the use of a scoring protocol based on physical examination and imaging modalities allowed development of a joint score applicable to objective joint assessment and prediction of arthroscopic treatment outcomes, connecting it with owner satisfaction. The most common findings were determined in each performed examination, especially in the early phase of osteoarthritis. Besides that, medical history, ultrasonographic and arthroscopic examination were thought to be more relevant to treatment outcome and owner satisfaction.

\section{Conflict of Interest}

The authors declare there are no conflicts of interest.

\section{Ethics Statement}

The scientific research was approved by the Ethics Committee in the use of animals of the School of Veterinary Medicine and Animal Science of University of São Paulo, protocol number: 2093/2010.

\section{Acknowledgements}

To FAPESP (São Paulo Research Foundation), and the School of Veterinary Medicine and Animal Science - University of São Paulo. To all participating colleagues and staff and CAPES (Coordenação de Aperfeiçoamento de Pessoal de Nível Superior).

\section{References}

Baccarin RYA, Pereira MA, Roncati NV, Bergamaschi RRC, Hagen SCF. Development of osteochondrosis in Lusitano foals: A radiographic study. Can Vet J. 2012;53(10):107984. PMid:23543926.

Baxter GM. Adams and Stashak's lameness in horses. 6th ed. Ames, Iowa: John Wiley \& Sons Wiley-Blackwell; 2011.

Davidson EJ. Lameness evaluation of the athletic horse. Vet Clin North Am Equine Pract. 2018;34(2):181-91. http:// dx.doi.org/10.1016/j.cveq.2018.04.013. PMid:30007446.

Debastiani G, Dela Côrte FD, Brass KE, Kommers GD, Denoix JM. Association of ultrasound and anatomopathologic findings of equine metacarpophalangeal lesions. J Equine Vet Sci. 2014;34(10):1218-25. http://dx.doi.org/10.1016/j. jevs.2014.08.006.

De Lasalle J, Alexander K, Olive J, Laverty S. Comparisons among radiography, ultrasonography and computed tomography for ex vivo characterization of stifle osteoarthritis in the horse. Vet Radiol Ultrasound. 2016;57(5):489-501. http://dx.doi.org/10.1111/vru.12370. PMid:27237699.
Denoix JM, Audigié AF. Ultrasonographic examination of joints in horses. In: American Association of Equine Practitioners. Proceedings of the 47th Annual Convention of the American Association of Equine Practitioners; 2001 Nov 24-28; San Diego, CA. Lexington (KY): AAEP.

Ireland JL, Clegg PD, Mckane SA, Chandler KJ, Pinchbeck GL. Comparison of owner-reported health problems with veterinary assessment of geriatric horses in the United Kingdom. Equine Vet J. 2012;44(1):94-100. http://dx.doi. org/10.1111/j.2042-3306.2011.00394.x

Jacquet S, Robert C, Valette JP, Denoix JM. Evolution of the radiological findings detected in the limbs of 321 young horses between the ages of 6 and 18 months. Vet J. 2013;197(1):58-64. http://dx.doi.org/10.1016/j.tvjl.2013.03.042. PMid:23660154.

Keen HI, Conaghan PG. Ultrasonography in osteoarthritis. Radiol Clin North Am. 2009;47(4):581-94. http://dx.doi. org/10.1016/j.rcl.2009.04.007. PMid:19631070. 
Kidd JA, Fuller C, Barr ARS. Osteoarthritis in the horse. Equine Vet Educ. 2001;13(4):160-8. http://dx.doi. org/10.1111/j.2042-3292.2001.tb00082.x.

Kirker-Head CA, Chandna VK, Agarwal RK, Morris EA, Tidwell A, O'Callaghan MW, Rand W, Kumar MSA. Concentrations of substance $\mathrm{P}$ and prostaglandin E2 in synovial fluid of normal and abnormal joints of horses. Am J Vet Res. 2000;61(6):714-8. http://dx.doi.org/10.2460/ ajvr.2000.61.714. PMid:10850851.

Lawson JS, Bolt DM, May S, Smith AJ, Felstead CW, Weller $\mathrm{R}$. Detection of effusion on radiographs of horses. Vet Rec. 2012;170(13):336-40. http://dx.doi.org/10.1136/vr.100392. PMid:22266684.

Lepeule J, Robert C, Bareille N, Valette JP, Jacquet S, Seegers $\mathrm{H}$, Denoix JM. A reliable severity scoring system for radiographic findings in the limbs of young horses. Vet J. 2013;97(1):52-7. http://dx.doi.org/10.1016/j.tvjl.2013.03.041. PMid:23672814.

Machado VMV, Aguiar ACS, Viana GF, Crosignani NO, Puoli Filho JNP. Diagnostic value of computed tomography, radiography and ultrasonography in metacarpophalangeal joint disorders in horses. Arq Bras Med Vet Zootec. 2016;68(1):66-72. http://dx.doi.org/10.1590/1678-4162-7899.

Martins EAN. Study of chitosan-glycerol phosphate gel biocompatibility in experimentally induced equine talus osteochondral defect. [PhD dissertation]. School of Veterinary Medicine and Animal Science, University of São Paulo: São Paulo; 2010.

McIlwraith CW, Frisbie DD, Kawcak CE. The horse as a model of naturally occurring osteoarthritis. Bone Joint Res. 2012;1(11):297-309. http://dx.doi.org/10.1302/20463758.111.2000132. PMid:23610661.

McIlwraith CW, Fortier LA, Frisbie DD, Nixon AJ. Equine models of articular cartilage repair. Cartilage. 2011;2(4):317-26. http://dx.doi.org/10.1177/1947603511406531. PMid:26069590.

Minshall GJ. Ultrasound and joint disease. In: British Equine Veterinary Association Congress. Proceedings of the 47th British Equine Veterinary Association Congress; 2008 Sep 10-13; Liverpool, UK. Liverpool (UK): BEVA; 2008.

Muttini A, Vantini C, Cuomo A. Arthroscopy in the horse. Vet Res Commun. 2003;27(1, Suppl 1):79-83. http://dx.doi. org/10.1023/B:VERC.0000014122.81514.88. PMid:14535373.
Nelson BB, Kawcak CE, Goodrich LR, Werpy NM, ValdésMartínez A, Mcilwraith CW. Comparison between computed tomographic arthrography, radiography, ultrasonography, and arthroscopy for the diagnosis of femorotibial joint disease in Western performance horses. Vet Radiol Ultrasound. 2016;57(4):387-402. http://dx.doi.org/10.1111/vru.12366. PMid:27170533.

R Core Team [Internet]. R. A language and environment for statistical computing. Vienna, Austria: R Foundation for Statistical Computing; 2014 [ cited 2014 May 20]. Available from http://www.R-project.org/

Rasera L, Macoris DG, Canola JC, Aita AC, Gomes TLS. Early radiographic and ultrasonographic changes in equine experimental osteoarthritis. Arq Bras Med Vet Zootec. 2007;59(3):634-40. http://dx.doi.org/10.1590/S010209352007000300013 .

Reef VB, Whittier M, Allam LG. Joint ultrasonography. Clinical Techniques in Equine Practice. 2004;3(3):256-67. http://dx.doi.org/10.1053/j.ctep.2005.02.003.

Sarin JK, Brommer H, Argüelles D, Puhakka PH, Inkinen SI, Afara IO, Saarakkala S, Töyräs J. Multimodality scoring of chondral injuries in the equine fetlock joint ex vivo. Osteoarthritis Cartilage. 2017;25(5):790-98.

Souza MV. Osteoarthritis in horses-Part 1: relationship between clinical and radiographic examination for the diagnosis. Braz Arch Biol Technol. 2016;59:1-9. http:// dx.doi.org/10.1590/1678-4324-2016150024.

Vanderperren K, Martens A, Haers H, Duchateau L, Saunders JH. Arthroscopic visualization of the third metacarpal and metatarsal condyles in the horse. Equine Vet J. 2009;41(6):52633. http://dx.doi.org/10.2746/042516409X386976. PMid:19803046.

Vanderperren K, Saunders JH. Diagnostic imaging of the equine fetlock region using radiography and ultrasonography. Part 2: the bony disorders. Vet J. 2009a;181(2):123-36. http:// dx.doi.org/10.1016/j.tvjl.2008.01.017. PMid:18467136.

Vanderperren K, Saunders JH. Diagnostic imaging of the equine fetlock region using radiography and ultrasonography. Part 1: soft tissues. Vet J. 2009b;181(2):111-22. http://dx.doi. org/10.1016/j.tvjl.2008.03.005. PMid:18445536.

Venables WN, Ripley BD. Modern applied statistics with S [Internet]. 4th ed. Switzerland: Springer; 2002 [cited 2014 May 20]. 465 p. Available from: http://www.stats.ox.ac.uk/ pub/MASS4/ 
Financial Support: FAPESP (São Paulo Research Foundation), and CAPES (Coordenação de Aperfeiçoamento de Pessoal de Nível Superior).

Authors Contributions: Conceptualization: Marilene Machado Silva, Stefano Carlo Filippo Hagen. Data Curation: Marilene Machado Silva, Cynthia do Padro Vendruscolo, Raquel Yvonne Arantes Baccarin. Funding acquisition: Marilene Machado Silva, Luis Claudio
Lopes Correia da Silva. Investigation and Methodology: Marilene Machado Silva, Stefano Carlo Filippo Hagen, Cynthia do Padro Vendruscolo, Raquel Yvonne Arantes Baccarin, Júlio David Spagnolo, Ana Lúcia Miluzzi Yamada, Fernanda de Castro Stievani, Luis Claudio Lopes Correia da Silva. Supervision: Luis Claudio Lopes Correia da Silva. Writing, Review and Editing: Marilene Machado Silva, Fernanda de Castro Stievani, Ana Lúcia Miluzzi Yamada. 